\title{
Is There a Culture War? Conflicting Value Structures in American Public Opinion
}

\author{
WILLIAM G. JACOBY Michigan State University
}

\begin{abstract}
7 his article examines the "culture war" hypothesis by focusing on American citizens' choices among a set of core values. A geometric model is developed to represent differences in the ways that individuals rank-order seven important values: freedom, equality, economic security, social order, morality, individualism, and patriotism. The model is fitted to data on value choices from the 2006 Cooperative Congressional Election Study. The empirical results show that there is an enormous amount of heterogeneity among individual value choices; the model estimates contradict any notion that there is a consensus on fundamental principles within the mass public. Further, the differences break down along political lines, providing strong evidence that there is a culture war generating fundamental divisions within twenty-first century American society.
\end{abstract}

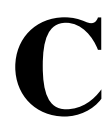
ulture is a multifaceted concept. But, one approach that has achieved some prominence in political science defines "culture" as the set of values that are salient within a given society. Building upon this idea, a heterogeneous nation like the United States could easily generate a variety of distinct and different value orientations within its population. If these differing value structures imply mutually exclusive social arrangements and societal goals, they could produce the kinds of fundamental disagreements that have been characterized as "culture wars" in recent scholarly and popular commentary. This article provides an empirical investigation of these ideas, using some unique data obtained from the 2006 Cooperative Congressional Election Study.

The analysis below will use individual value choices as the raw material to create a structural model of the predominant value preferences that exist within the American mass public. The model, itself, is a geometric representation with features that are fairly intuitive and easy to interpret. And, the elements of the model are amenable to systematic analysis using a set of statistical tools that are designed for use with angular data.

The results from the empirical analysis provide strong evidence for the culture wars hypothesis. Americans' value choices are highly heterogeneous, with

William G. Jacoby is Professor, Department of Political Science, Michigan State University (jacoby@msu.edu).

Special thanks go to Saundra K. Schneider. This project could not have been completed without her assistance and support. I also appreciate very much the excellent comments and suggestions that I received from Paul Abramson, Joseph Bafumi, David Hill, Christopher Larimer, Paul Quirk, Kyle Saunders, the anonymous APSR referees, and the members of the MSU Political Science Research Group: Rebecca Bromley-Trujillo, Seo Youn Choi, David Ciuk, Dominique Lewis, Robert Lupton, Niccole Pamphilis, Kurt Pyle, and Daniel Thaler. Earlier versions of this article were presented at the 2011 Annual Meetings of the American Political Science Association, the University of Georgia Department of Political Science, the Center for Political Studies Interdisciplinary Workshop on Politics and Policy (University of Michigan), the Michigan State University Political Science Friday Seminar Series, the 2012 Annual Meetings of the Midwest Political Science Association, the University of Oklahoma Department of Political Science, the 2012 Elections, Public Opinion, and Parties Conference, and the University of North Carolina American Politics Research Group. Replication data and materials for this study are available online at http://thedata.harvard. edu/dvn/dv/JacobyData. many conflicting preferences about fundamental principles like freedom, equality, and the like. Furthermore, the variability breaks down along social and political lines. These findings have important implications for understanding the nature of conflict and disagreements within the contemporary American political system.

The remainder of the article is organized as follows: The next section introduces the basic concepts addressed in this study and considers why existing research may leave some important questions unanswered. The two sections after that develop the geometric model used to represent individual value choices and describe the data that are used in the analysis. The three sections after that present the empirical analysis by estimating the geometric model of American political culture, examining the religious and political foundations of variability in value choices, and assessing the sources and magnitude of value conflict. Finally, the concluding section considers this study's implications for scholarly understandings of values-based cultural disagreements and emphasizes the clearly political nature of the culture war that does seem to exist in twentyfirst century America.

\section{BACKGROUND}

Culture is critically important to an understanding of public opinion because it provides the context within which political beliefs and attitudes exist (Bennett 1980). In effect, culture delimits the "boundaries" of legitimate opinions within a society (Wildavsky 1987). While such statements emphasize the importance of culture, they beg the question of what culture really is.

\section{Culture, Values, and Politics}

In fact, there are several theoretical perspectives on culture that exist within the political science literature. The classic description of American culture is liberalism tempered by democracy, as originally described in detail by Tocqueville and extolled by more recent theorists such as Hartz (1955) and Katznelson (1996). Critics, however, charge that the emphasis on liberal democracy masks a variety of cultural challenges that 
have arisen throughout American history, generally from groups that do not enjoy the full benefits of liberal society. So, for example, Rogers Smith argues that "the distinctive feature of American political culture has not been its liberal, republican, or 'ascriptive Americanist' elements but, rather, (a) more complex pattern of apparently inconsistent combinations of traditions ...(1993, 558)."

From an empirical perspective, Almond and Verba's early (1963), but still influential, comparative work emphasizes societal orientations toward political contenders and the institutions of power within a polity. Culture, itself, emerges from the particular combination of individual orientations (which Almond and Verba classified as participant, subject, and parochial) that exists in a given society. Inglehart (1997) argues that cultures vary according to the degree to which basic human needs are met. Societies can be arrayed along a continuum that ranges from those in which attempts to address basic human needs dominate everyday life to cultures in which higher levels of socioeconomic wellbeing enable citizens to focus on post-material values of self-fulfillment. Still another distinctive view of culture is provided in the work of Douglas and Wildavsky (1982), who argue that societies inevitably experience two distinct dimensions of social organization, which they call "group" and "grid." The former involves the degree to which people view themselves as individuals or members of a collective social entity, and the latter focuses on the degree to which people are autonomous decision-makers or limited by externally imposed constraints (e.g., Ripberger, Jenkins-Smith, and Herron 2011).

The preceding theories all provide distinctive views of culture, and each has generated a voluminous literature. But, a common thread across these different lines of work is that culture is manifested in the values that are salient in a society. Values, themselves, are defined at the individual level as each person's abstract conceptions about the desirable and undesirable endstates of human life (Rokeach 1973; Schwartz 1996; Schwartz and Bilsky 1987). Thus, political culture could be viewed as the general framework of values that characterizes the orientations of a nation's citizens.

Culture is also an important source of the issues that arise in day-to-day political life (e.g., Gastil et al. 2011). Within the bounds defined by cultural standards, there is likely to be conflict because the desirable end-states implied by values are, to varying degrees, mutually exclusive of each other. That is, the consequences of attaining one value (e.g., freedom) will almost certainly restrict the degree to which some other desirable endstate is achieved (e.g., equality).

This basic tenet of societal interaction explains why values are of fundamental importance to politics. Philosophers, collective action theorists, and policy analysts agree that issue conflict inherently involves clashes of competing value systems (e.g., Berlin 1969; Chong 2000; Stone 2012). As stated in David Easton's well-known phrase, politics involves disagreements about the "authoritative allocation of values (Easton 1965, emphasis added)."

\section{Culture War?}

Despite the potential for conflict based upon values, the traditional view is that the United States is characterized by a general consensus on fundamental orientations (Dahl 1989; Devine 1972; McClosky and Zaller 1984). Recently, however, the existence of this societal consensus has been called into question. Various commentators have suggested that a "culture war" exists, in which "...Americans are taking sides in a civil war between incompatible views of the American way of life (Baker 2005, p. 65)." Sociologist James Hunter provided one of the first systematic statements of the culture wars hypothesis: "The divisions of political consequence today are ...the result of differing worldviews. ... (The conflict revolves) around our most fundamental and cherished assumptions about how to order our lives-our own lives and our lives together in this society (1991, p. 42)." Thus, Hunter succinctly points out that the culture war is disagreement about basic value orientations and also that it has immediate political consequences.

The idea of a culture war definitely has had great resonance in American electoral politics over the past two decades. In his famous speech to the 1992 Republican National Convention, Patrick Buchanan stated:

There is a religious war going on in this country. It is a cultural war, as critical to the kind of nation we shall be as the Cold War itself. For this war is for the soul of America.

While more recent candidates have not used the specific term as freely, they have focused directly on many of the themes associated with cultural conflict, such as abortion, contraception, gay rights, global warming, and traditional lifestyles. As evidence of this, the 2012 primary battles within the Republican party were often heralded by the press as a direct manifestation of the culture war (e.g., Henderson 2012; Schlesinger 2012). Journalists continued using this theme on into the general election campaign (e.g., Gerson 2012; Stein and Terkel 2012), with a prominent New York Times article declaring that the culture war has now moved in "from the fringe" to become a central issue in American electoral politics (Nagourney 2012).

Outside the electoral setting, the rise of the Tea Party movement can be seen as another manifestation of themes often associated with the culture war. Meckler and Martin (2012) and Skocpol and Williamson (2012) both emphasize that Tea Party activism stems from a belief that American society has abandoned the ideas espoused by the founders. The Tea Party perspective is a distinctive worldview among a subset of American society, organized largely around opposition to other subgroups that they believe to be fundamentally inconsistent with traditional American values and culturein short, precisely the same idea that is subsumed within the current usage of the term, "culture war."

While there has been a substantial literature devoted to the culture war hypothesis, the empirical evidence that has been mustered and the scholarly interpretations that have been offered are highly mixed. For 
example, some researchers identify fundamental contradictions in the moral and religious orientations of subgroups within the American population. These differences are rooted in conceptions about the nature and objectives of human life (e.g., Barker, Hurwitz, and Nelson 2008; Barker and Tinnick 2006; Guinness 1993; Hunter 1991; Lakoff 2002). Similarly, a number of political scientists have pointed to sharp increases in the polarization of recent American political discourse and attitudes within the mass public (e.g., Abramowitz and Saunders 2008; Layman, Carsey, and Horowitz 2006) as symptomatic of unusually profound disagreements about the direction in which American society should be moving. Barker and Carman (2012) make an even broader argument that the culture war has profound effects on public understandings of politics, creating sharp and consequential differences in preferences for representational styles.

In contrast to these findings of conflict, a number of sociologists raise pointed questions about the validity of the culture war hypothesis (e.g., Williams 1997; Wolfe 1998). For example, Evans (1996) argues that traditional theories about differences among status groups account for patterns of opinion disagreement more accurately than do accounts of fundamentally conflicting worldviews across polarized segments of society. Similarly, both DiMaggio, Evans, and Bryson (1996) and Davis and Robinson (1996) provide evidence that the extent of polarization has been overstated, with sharp disagreements confined only to specific issues with explicit religious implications. From a somewhat different perspective, Baker (2005) employs the World Values Survey to show that Americans are united on fundamental principles and he concludes that "...the culture war is largely a fiction (p. 109)."

Some political scientists also emphasize the continued importance of centrism for understanding American public opinion. Fiorina, Abrams, and Pope (2006) have been the most vocal advocates of this position, stating that allegations of a culture war in America "...range from simple exaggeration to sheer nonsense (2006, 8)." Gelman (2008) similarly questions the validity of dividing the United States into a dichotomy of "red states" and "blue states." He argues that a more accurate picture of electoral conflict would emphasize the mixed orientations that characterize virtually all parts of the country.

\section{Limitations of Previous Research}

Scholars definitely express strong disagreements about the existence of a culture war. But, none of the previous efforts have really gotten to the heart of the issue, for several reasons: First, it is difficult to deny that some polarization exists in public opinion and political preferences. And while this could be a manifestation of a culture war, it may also have arisen from other causes. For example, Levendusky's (2009) theory of partisan "sorting" provides an explanation for the existence of greater ideological clarity in Democratic and Republican ranks that does not require stronger contrasting views on the two sides.
Second, a culture war may not be manifested clearly in political issues. Skocpol and Williamson (2012) show that Tea Party activists often support policies and legislation that are not associated with conservatives (e.g., Social Security, Medicare, and generous benefits targeted toward identifiable needy groups in society), despite their distinctive views about the problems of American society and politics. Thus, it is not entirely clear that disagreements about specific policy issues map cleanly onto the divisions that should be associated with a culture war.

Third, most of the research on polarization in American politics focuses on unidimensional ideological or partisan conflict. However, fundamental sociopolitical orientations are typically depicted with multidimensional structures. For example, the value configurations presented by Rokeach (1973) and Schwartz (1996) are both two-dimensional, with the former organized according to support for liberty and equality, and the latter structured by support for change and relative concern for self versus others. Several researchers have also argued for multidimensional conceptions of ideology, with distinctions between economic cleavages on the one hand and moral/social distinctions on the other (Swedlow and Wyckoff 2009; Treier and Hillygus 2009). Similarly, culture theories generally posit multiple cleavages that exist simultaneously. So, Inglehart (1997) finds two dimensions, tapping distinctions between religious versus secular and traditional versus post-material societies. And, the Douglas-Wildavsky (1982; Wildavsky 1987) culture theory uses the group and grid dimensions to identify four separate, potentially conflicting, citizen orientations that exist simultaneously: hierarchs, individualists, egalitarians, and fatalists. The problem is that it may not be possible to transform these kinds of complex preferences and orientations onto a single bipolar dimension like the liberal-conservative continuum. If so, then research that focuses on the latter will inevitably miss elements of any culture war that may exist.

Fourth, works that have approached the culture war hypothesis from a perspective based on values may have measured the latter in ways that are not fully consistent with the ways that values impinge on human behavior. Much of the social scientific research on values and public opinion is based upon data in which people rate the importance of individual values (e.g., Feldman 1988; Baker 2005; Goren, Federico, and Kittilson 2009). The problem with this approach is that longstanding psychological theories hold that specific values do not operate in isolation from other values. Instead, people maintain feelings about multiple values, with comparisons between values providing the cues for how to behave in any situation where the values have relevance (e.g., Rokeach 1973; Schwartz 1996; Schwartz and Bilsky 1987; Verplanken and Holland 2002). This view is becoming increasingly prominent in political science as well (e.g., Ciuk and Jacoby 2014; Davis and Silver 2004; Inglehart 1997; Jacoby 2006; Peffley, Knigge, and Hurwitz 2001; Searing 1978; Sniderman et al. 1996; Swedlow and Wyckoff 2009). 
In order for values to provide such guidance, people must have feelings about the relative importance of different values. And, since it is assumed that people have feelings about multiple values, this leads naturally to the idea that they possess rank-ordered value structures in which values are mentally arrayed from most important to least important. The exact ranking of the values differs from one person to the next (Rokeach 1973); that is precisely what leads to variability in human behavior. Individuals engage in activities that promote values near the top of their own importance ranking and avoid activities associated with values near the bottom of their respective hierarchies (Schwartz 1996).

Extrapolating from individuals to the societal level, a nation's political culture is characterized by the value structures that predominate within its society. If these structures are similar from one person to the next, the political culture will be consensual. But, if structures vary markedly - producing serious disagreements about which values are important and which values are not - then it could signal the kind of fundamentally conflicting worldviews that characterize a culture war. Again, however, none of the previous research on this topic has examined directly the structure of value choices in the American public.

\section{A GEOMETRIC MODEL OF INDIVIDUAL VALUE CHOICES}

In order to construct a model of political culture (or at least that component of political culture that is rooted in values), we must have information about the individual value structures that exist within the society under investigation. These value structures are manifested in each person's importance rankings for a common set of values, all of which are salient within the culture. The analytic problem is to represent individuals' rankordered value choices across the entire mass public in a compact and comprehensible manner.

I will use a geometric approach to accomplish the preceding objective: Values will be shown as points and individuals as vectors within a common space. The points and vectors are arranged so that, to the greatest extent possible, each vector points toward the values that the individual believes are most important, and away from those that he or she considers to be least important. More precisely, each person's vector will be oriented such that his/her importance ratings for the values are monotonically related to the order in which the value points project onto his/her vector.

Figure 1 shows a very simple example of such a model, based upon hypothetical information about two individuals" (labeled " 1 " and " 2 ") feelings about three values (labeled "A," "B," and "C"). A table containing the raw data is shown in the top half of the figure. There, we can see that individual 1 says value $\mathrm{A}$ is most important, value $\mathrm{C}$ is second-most important, and value $\mathrm{B}$ is least important. In contrast, individual 2 rates $\mathrm{B}$, $\mathrm{A}$, and $\mathrm{C}$, from most to least important. The bottom half of the figure shows a two-dimensional geomet- ric space that is consistent with the information from the individuals' rank-orders for the values; the space contains three points representing values $\mathrm{A}, \mathrm{B}$, and $\mathrm{C}$ along with two vectors for individuals 1 and 2 . The dotted line segments running from the value points to the two vectors show the perpendicular projections. ${ }^{1}$ Notice that, starting from the terminal point of each vector (i.e., the end with the arrowhead), the order of the projections corresponds to the entries in each row of the data matrix. On individual 1's vector, the projection for value $\mathrm{A}$ comes first, followed by $\mathrm{C}$ and then B. On individual 2's vector, the projection for value $\mathrm{B}$ is closest to the tip, followed by those for values $\mathrm{A}$ and $\mathrm{C}$, respectively.

Any real model will contain far more than two vectors and more than three points. In fact, a much larger dataset than this simple example is necessary in order to fix the relative positions of the vectors and points. But, the basic principle for locating these geometric elements remains the same: The vector orientations relative to the point locations must conform to the individuals' rankings of the values.

This kind of model has several advantageous features. First, the structuring of the values (as represented by the point configuration) is determined empirically; it is not based upon any a priori specification of how the values differ from each other. This is important because it ensures that the model represents the ways that people actually do think about the respective values, rather than the researcher's preconceived theoretical expectations. Second, the model incorporates and represents each person's full importance ranking across the entire set of values. This is critical because it provides a succinct depiction of individual value structures which, when aggregated, characterize the predominant culture within a society. Third, the input data for the model are simple rank-orders, which should be fairly easy for survey respondents to provide. But, the projections from the value points onto the individual vectors have metric properties, which means that they reveal information about relative degrees of importance that individuals assign to the respective values. Finally, the individual vector orientations comprise directional data which possess features (to be explained below) that facilitate analysis of variability in value preferences. $^{2}$

\footnotetext{
${ }^{1}$ The value points actually project onto the line that contains the vector, rather than the vector itself. This does not affect the substantive interpretation.

${ }^{2}$ The geometric structure illustrated in the lower half of Figure 1 is sometimes called the MDPREF model, an acronym for "multidimensional preference scaling" (e.g., Carroll 1972). A supplemental report to this article lays out a procedure for estimating the value point locations and individual vector orientations from a dataset containing the individuals' preference rankings for the values. The procedure uses a strategy called "alternating least squares, optimal scaling" (or ALSOS) to provide the best-fitting (in the least-squares sense) estimates of the value points and individual vectors. The estimation procedure also provides a fit measure that can be interpreted as an $R^{2}$ value, or the squared correlation between the model estimates and the rank-orders from the input data.
} 


\section{FIGURE 1. Hypothetical Example of Geometric Model to Represent Value Importance Rankings}

Part 1: Data on two hypothetical individuals' value structures. Cell entries are importance rankings for three values (labelled $\mathrm{A}, \mathrm{B}$, and $\mathrm{C}$ ), with larger numbers corresponding to more important values.

\begin{tabular}{cccc}
\hline \hline & & & \\
& & & \\
& & & \\
& $\mathrm{A}$ & $\mathrm{B}$ & $\mathrm{C}$ \\
\hline Individual 1: & 3 & 1 & 2 \\
Individual 2: & 2 & 3 & 1 \\
\hline
\end{tabular}

Part 2: Geometric model of individual value structures. Value points project onto the lines collinear to the individuals' vectors in the order corresponding to each person's importance rankings.

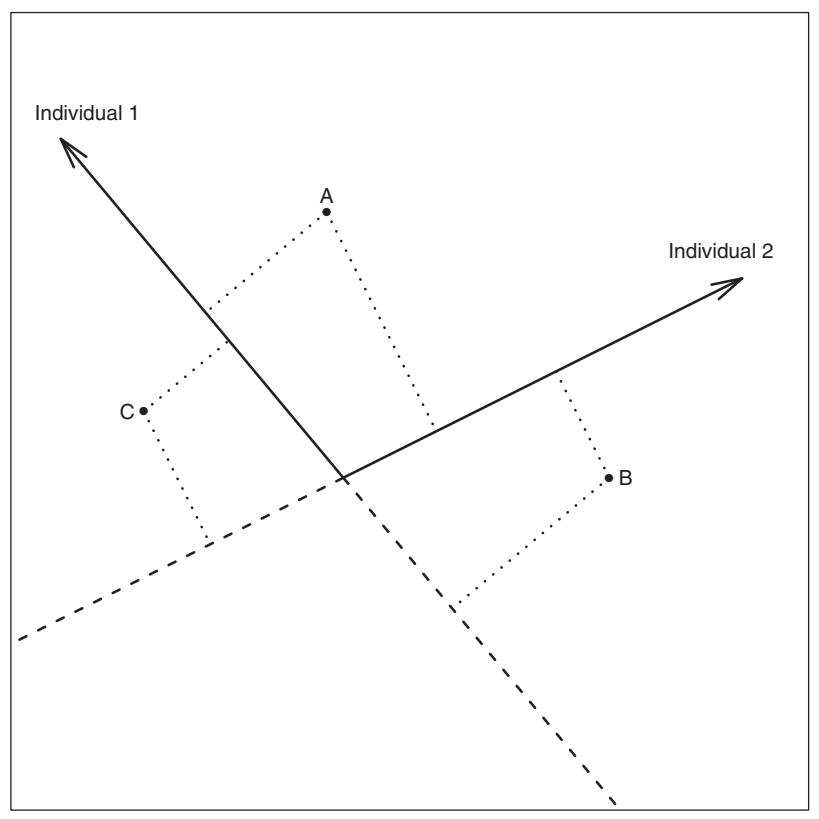

\section{DATA}

The vector model of value choices will be fitted to data drawn from the 2006 Cooperative Congressional Election Study (CCES), an internet survey carried out by Polimetrix, Inc. The component of the survey used here involves a nationally representative sample of 1,000 American adults. ${ }^{3}$ The CCES interview schedule con-

${ }^{3}$ The 2006 CCES is a large collaborative project involving 36 research teams comprised of scholars from 39 universities. Prior to the data collection, a complex procedure was used to draw a representative sample of respondents from a huge panel of potential survey tains items that elicit information about respondents' general political orientations, issue attitudes, and sociodemographic characteristics. But, more important

interviewees. Matching procedures were then employed to insure that the CCES sample conforms to the demographic profile of the American adult population. The full CCES sample has 38,443 respondents. The data used in the current analysis comprise a randomly selected subset of size 1,000 from the overall sample. Vavreck and Rivers (2008) provide a detailed discussion of the design, content, and sample characteristics of the 2006 CCES. The website for the CCES is located at http://projects.iq.harvard.edu/cces/. 


\section{TABLE 1. Values and Definitions Shown to Respondents in Post-Election Wave of the 2006 Cooperative Congressional Election Study. In the Actual Administration of the Survey, the Order of the Values was Randomized Across Respondents}

FREEDOM, that is the widest liberty possible for everyone to act and think as they consider most appropriate.

EQUALITY, that is making sure that everyone has the same chance to get ahead in life.

ECONOMIC SECURITY, that is making sure that everyone has a steady job, a decent income, and a reasonable standard of living.

MORALITY, that is people living according to the rules that most people agree constitute decent human behavior.

INDIVIDUALISM, that is everyone getting ahead in life on their own, without extra help from government or other groups.

SOCIAL ORDER, that is being able to live without fear, in a safe, peaceful society where the laws are respected and enforced.

PATRIOTISM, that is looking beyond our own personal interests and doing things that honor, respect, and protect our nation as a whole.

for present purposes, the post-election wave of the 2006 CCES asked respondents to rank-order the importance of seven values: Freedom; equality; economic security; morality; social order; individualism; and patriotism. These particular values were used because of their relevance to the philosophical foundations of the American political system along with their salience in contemporary political discourse.

The procedure for obtaining rank-ordered value choices was first used in a political science context by Jacoby and Sniderman (2006). During the internet survey, the CCES respondents were presented with a screen showing the following statement:

On the next few screens, we will show you a list of values, such as freedom, equality, and so on. Nearly everyone agrees that all of these values are important. However, sometimes we have to choose one value over another. From the list of values, please select the single value that you think is the most important.

Starting with the next screen, respondents used radio buttons to select the most important value from the list that appeared on the screen. The order of the values in the list was randomized for each respondent. But, the contents of the list for the full set of seven values is shown in Table 1. After selecting the most important value from the list of seven, the respondents were shown another screen that started with the question, "Now, of the values that remain, which one would you say is the most important?" The question was followed by a list of the six values that were not chosen on the preceding screen. This process was repeated, successively eliminating chosen values from the list, until respondents were asked to choose from a list of only two values. Of course, the final, nonchosen value falls at the bottom of each respondent's rank-order.

As Table 1 shows, respondents were also given a brief definition of each value. Obviously, these values represent very complex and multifaceted ideas; it is almost certainly impossible to encapsulate a complete understanding of any one of these values into a single short phrase. But, it seems likely that most citizens react to these values as symbols with heuristic utility (e.g.,
Bennett 1980) rather than as highly nuanced philosophical constructs. Still, individuals could vary widely in their personal ideas about the meanings of specific value terms. Such interpretational variability could be confounded with variability in the feelings of personal importance about the values. To avoid this problem, it has become accepted practice in empirical values research to provide definitions for values, in order to reduce extraneous variability in the responses (Sears, Huddy, and Schaffer 1983).

The empirical analysis will be confined to the 775 CCES respondents who gave complete rank-orders. Among these, there are 623 distinct orderings that show up in the data. Thus, there is a great deal of heterogeneity in choices across individuals.

Some scholars have expressed concerns that rankorders may force respondents to choose among values that they believe to be equally important (e.g., Alwin and Krosnick 1985; Maio et al. 1996). Fortunately, this does not appear to be a serious problem, either as a general aspect of value rankings or with the particular rank-orders used in the present study. Ciuk and Jacoby (2014) use the method of triads (i.e., respondents are presented with all subsets of three values from a set of values, and asked to identify the most- and least-important value in each subset) on national-level survey data obtained through the TESS Program to obtained replicated comparisons between pairs of values. Their results show that the vast majority of survey respondents provide value choices that are consistent across replications and transitive across choices, neither of which would be the case if people feel indifference or ambivalence and, therefore, are unable to make "real" choices (also see Jacoby and Ciuk 2014). Furthermore, inconsistent and intransitive value choices are most likely to occur among less sophisticated respondents-precisely where the quality of survey responses is most likely to be compromised (Jacoby 2006). Jacoby (2011) also exploits the panel study nature of the 2006 CCES to show that the value rankings used in the present study (which were collected during the second panel wave) are highly consistent with rankings constructed from the same respondents' pairwise value choices obtained in the first panel 


\begin{tabular}{lccccccr}
\multicolumn{6}{l}{ TABLE 2. } & \multicolumn{7}{l}{ Distribution of Importance Ranks for the Seven Values } \\
\hline $\begin{array}{l}\text { Rank } \\
\text { Score: }\end{array}$ & Freedom & Equality & $\begin{array}{c}\text { Economic } \\
\text { Security }\end{array}$ & Morality & Individualism & $\begin{array}{c}\text { Social } \\
\text { Order }\end{array}$ & Patriotism \\
\hline 6 & 25.81 & 11.87 & 16.52 & 16.52 & 4.90 & 16.13 & 8.26 \\
5 & 15.74 & 17.29 & 14.97 & 15.10 & 6.71 & 19.61 & 10.58 \\
4 & 13.55 & 16.26 & 16.52 & 14.32 & 8.39 & 18.58 & 12.39 \\
3 & 14.06 & 14.84 & 13.42 & 13.29 & 9.81 & 17.94 & 16.65 \\
2 & 11.87 & 13.94 & 12.90 & 11.87 & 16.77 & 13.81 & 18.84 \\
1 & 10.06 & 12.26 & 13.29 & 15.74 & 19.87 & 8.77 & 20.00 \\
0 & 8.90 & 13.55 & 12.39 & 13.16 & 33.55 & 5.16 & 13.29 \\
\hline
\end{tabular}

Note: Cell entries in table are column percentages. The number of observations is 775 . For each value, the rank score indicates the number of values that were ranked lower than that value in an individual's importance ranking for the full set of seven values.

wave using the method of triads. In summary, individual value rankings do appear to provide reasonably accurate empirical representations of the respondents' "true" value choices.

Table 2 provides some initial descriptive information. Specifically, the table gives the distribution of rank scores for each of the values. For a given value, the rank score gives the number of values that are ranked lower than that value in an individual's full rank-order. Freedom is the most popular value, with the highest percentage of placements in the most important position $(25.81 \%)$ and the fewest in the least important position (only $8.9 \%$ ). In contrast, individualism has the largest percentage of least important placements (by a wide margin, at $33.55 \%$ ) and the smallest number of placements in the most important position (only $4.9 \%$ ). It is difficult to perceive any clear patterns in choices among the values that fall between these two extremes. Instead, it is probably accurate to say simply that nontrivial percentages of the respondents placed each of the values at each of the possible positions within the rank-order hierarchy. Is there any systematic structure within the full set of individual value choices? This is where the multidimensional preference model should provide useful insights, through its ability to represent succinctly the large amount of information contained in the 775 rank-orders.

\section{EMPIRICAL RESULTS}

Preliminary analysis indicated that a two-dimensional model would be appropriate for the CCES data on value choices. The $R^{2}$ for the two-dimensional representation is 0.804 , showing that it accounts for fourfifths of the total variance in the optimally scaled value importance rankings. ${ }^{4}$ The two-dimensional model is advantageous because it is amenable to visual inspection. In order to facilitate interpretation, the individual vectors are adjusted to a length of one. Hence, the vector terminal points will all fall along a unit circle. This

\footnotetext{
4 The fit is much worse for a unidimensional solution $\left(R^{2}=0.454\right)$ and the improvement for a three-dimensional solution is not great enough to justify the increased complexity $\left(R^{2}\right.$ for three dimensions is 0.876 , an increase of only 0.072 ).
}

adjustment has no substantive effect since the order in which the value points project onto the vectors is the same, regardless of the vector lengths.

\section{The Configuration of Values}

The estimated model is shown in Figure 2. Looking first at the value point configuration (shown by the labeled, solid points), the general rule for interpretation is that the distances between the points are related to the similarity with which the corresponding values are rated by the CCES respondents. Points that are close together represent values that receive similar importance rankings; those that are far apart tend to fall at markedly different positions in the importance ranks. From the figure, it appears that the seven values fall into three clusters (although one of these clusters is composed of a single point). First, freedom, equality, and economic security form a group near the right side of the central region. This is perfectly reasonable, since the first two values comprise the central elements in the American creed (e.g., Devine 1972, McClosky and Zaller 1984) while economic security is increasingly recognized as a vital precondition for achieving the maximum benefits from American society (e.g., Gilens 2012; Hochschild 1995).

A second group falls in the lower-left area, with patriotism and morality falling quite close to each other, and social order a little farther away, but still part of this cluster. This grouping, too, is understandable. Patriotism and morality are themes that play a prominent role in conservative rhetoric (e.g., Critchlow 2011). And while social order is generally desirable for most people, it has long been a more salient concern on the political right than on the left (e.g., Rossiter 1962).

Finally, the point for individualism is widely separated from the others, in the upper left of the space. This distinct positioning is due to the low rankings that it received from most of the respondents. ${ }^{5}$ Nevertheless,

\footnotetext{
5 This does not mean that respondents believe individualism is unimportant in absolute terms. In fact, when people are asked to rate separate values along a common importance scale, individualism receives scores that are comparable to those assigned to other values (e.g., Goren Federico, and Kittilson 2009). But, when asked to
} 


\section{FIGURE 2. Full Model of Value Preferences}

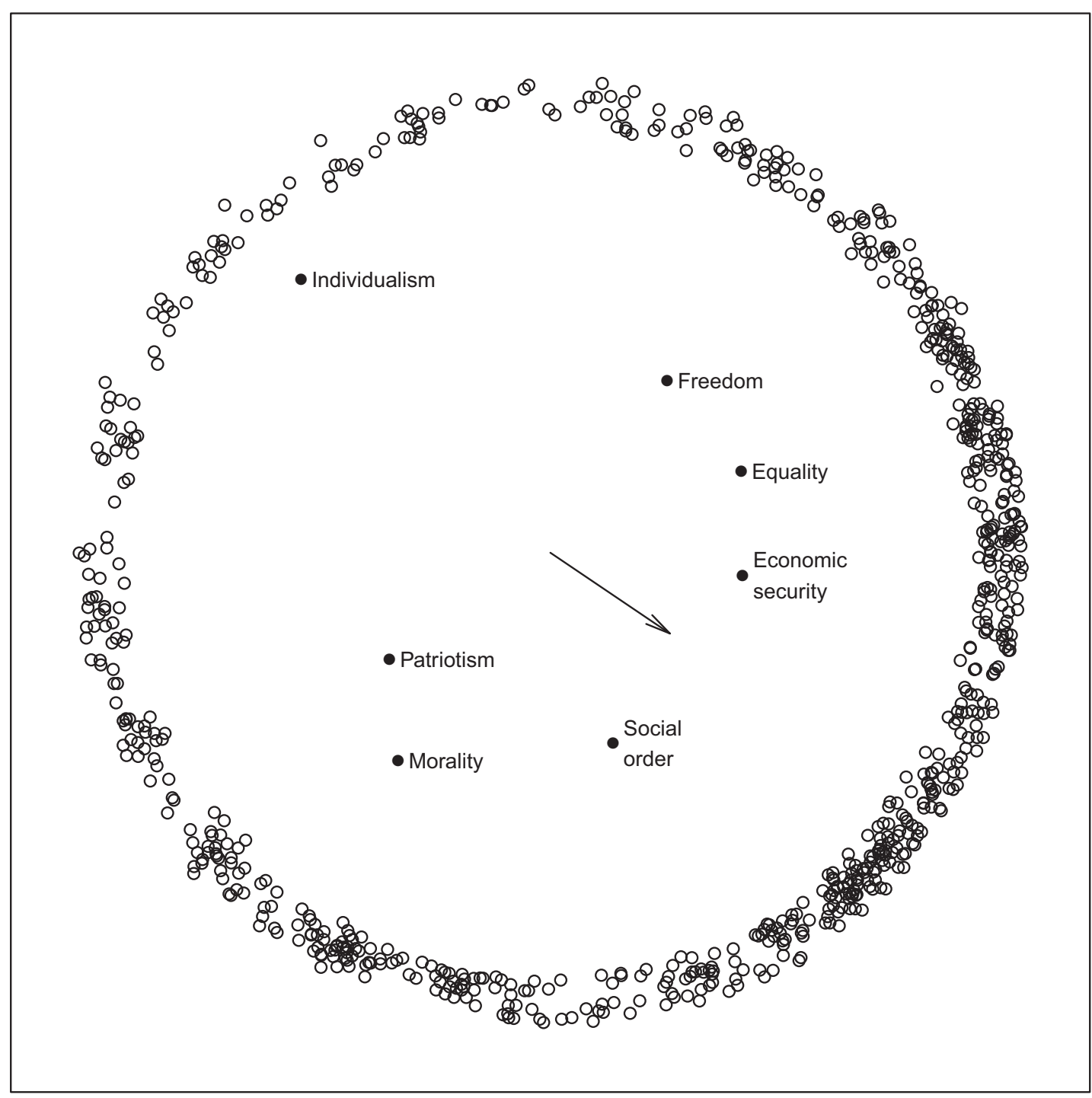

Notes: Value points are shown as solid circles. Only the terminal points of the individual respondent vectors are shown (as open circles). Vector terminal points are jittered to facilitate visual perception of relative concentrations of vectors around the unit circle. Figure also shows the mean direction vector, which is oriented about 34 degrees below the horizontal (or -0.594 radians). The mean resultant length, $\bar{R}$, is 0.321 .

it is slightly closer to the first group of points than to the second, perhaps reflecting the fact that individualism is also an important element of American cultural symbolism (Kluegel and Smith 1986; McClosky and Zaller 1984).

make explicit comparisons, many people state that individualism is less important than most other values. And, again, it is the choices between values that are important, rather than feelings about single values, in isolation from the others.

\section{Individual Importance Rankings}

Figure 2 also shows the terminal points for the vectors representing the individual respondents. (The shorter vector shown explicitly in the figure will be explained in the next section). Again, they are arrayed around a unit circle in the same space as the value points. Each vector terminus is shown as a small open circle; note that the terminal points are jittered to break up the exact plotting locations. This makes it easier to discern the variations in the concentrations of vectors around the space. 
As already explained, the order of the projections from the value points onto each vector corresponds to that individual's ranking of the values' importance. For present purposes, we are particularly interested in the angular separations between vectors. The smaller the angle between any two vectors, the more similar the value rankings of the two individuals and vice versa. In fact, the cosine of the angle between any two vectors is equal to the correlation in the predicted value rankings for those two people. Hence, vectors separated by angles less than 90 degrees represent positively correlated rankings while those separated by angles greater than 90 degrees correspond to negatively correlated rankings. Two collinear vectors pointing in the same direction (i.e., an angle of zero) would indicate a correlation of 1.0, while two collinear vectors pointing in opposite directions (i.e., an angle of 180 degrees) would indicate a perfect negative correlation, -1.0 .

The most prominent feature in the figure is the extreme variability in value choices, represented by the spread of vectors around the entire circumference of the circle. Far from consensus on basic values, the estimates in this model suggest that there is widespread disagreement about which values are more or less important. Looking closely at the jittered vector terminal points, there appear to be three areas that have relatively dense clusters of vectors. One of these occurs in the upper right quadrant of the unit circle, around the "2:00 position." People represented by vectors in this area rank freedom, equality, and economic security highest, followed by social order, and then some combination of individualism, patriotism, and morality. A second concentration of vectors falls in the lower right quadrant, between the 4:00 and 5:00 positions. While there is quite a bit of variability within this group, these people tend to rank social order highest, followed by morality and economic security. Patriotism and equality come next, with freedom just below that, and individualism once again appearing at the lowest position within most of their rank orders. The third cluster of vectors falls in the lower left quadrant; again, there is some variation within this general concentration, with one group near the 7:00 position and others spread out almost to the 9:00 position. The individuals in this general cluster are distinctive in that they rank morality, patriotism, social order, and individualism over the other three values.

The three clusters of individual vectors in Figure 2 are consistent with the culture theory of Douglas and Wildavsky (1982; Wildavsky 1987) and its relationship to ideology. For example, the first grouping of vectors (in the upper-right) reflects their individualistic and egalitarian orientations, with the former on the upper side of the cluster (i.e., closer to the $12: 00$ position) and the latter on the lower side (closer to the 3:00 position). The value rankings in the second cluster (i.e., within the lower-right of the figure) are consistent with the hierarchical orientation. The third cluster - the vectors arrayed within the lower-left of the figure-does not fit neatly into the fourfold classification from culture theory. But, it may reflect the separate communitarian perspective that was suggested by Janda, Berry, and
Goldman (2002) and confirmed empirically by Swedlow and Wyckoff (2009).

\section{Culture and Heterogeneity in Value Choices}

If culture is defined by the predominant value choices of a society, then how can this be operationalized in the geometric model of value importance rankings? Here, the analysis relies on statistical tools designed specifically for directional data (Schiffman, Reynolds, and Young 1981). And, since the vectors are normalized to unit length, they are frequently called "circular" data (Gill and Hangartner 2010). The approach I will use is to summarize the myriad value choices represented in Figure 2 by taking the mean direction of the individual vectors. ${ }^{6}$ As with any other average, the mean direction is intended to provide the single orientation that "best" reflects the orientations of the full set of vectors.

The length of the mean direction vector (called the "mean resultant length" and denoted $\bar{R}$ ) is also important because it is inversely related to the amount of angular separation in the set of vectors over which the mean is calculated. Because the individual vectors are set to unit length, $\bar{R}$ can range from 0 to 1 . If there is no variation in the directions, then the vectors will all be perfectly collinear, and the mean resultant length will be equal to that of the vectors themselves, or 1.0. Conversely, there are a number of situations that will result in a mean resultant length of zero; for example, $\bar{R}=0$ when half of the vectors have mirror image vectors that point in exactly the opposite direction. Thus, the smaller the mean resultant length, the greater the heterogeneity in value choices.

Along with the terminal points for the individual vectors, Figure 2 shows the actual mean vector for the full set of CCES respondents. Perhaps the most salient feature of the mean vector is its short length, at $\bar{R}=0.321$. This figure just confirms the previously noted existence of broad heterogeneity in feelings of value importance. There is little in the way of overall consensus about what is most important and what is least important in basic value orientations. American society is characterized by extreme levels of value disagreement rather than broad adherence to a set of common fundamental principles.

The value points project onto the mean vector with economic security first (i.e., most important), followed fairly closely by social order. Equality comes next, followed by freedom, morality, and patriotism; note that these three project very closely to each other, making their relative positions nearly indistinguishable. Individualism falls in last place, by a wide margin. This ordering of the mean importance ranks suggests that, to the extent that there is any common ground at all, the values component of American culture is dominated by the kinds of practical concerns associated with an orderly society in which peoples' material needs are

\footnotetext{
${ }^{6}$ The coordinates for the mean direction vector are obtained simply by taking the means of the individual vector coordinates on each dimension
} 
met, rather than lofty principles, codes of conduct, or feelings of obligation to society.

The array of value projections along the mean vector is somewhat surprising in terms of prior theory. For example, the trailing position of individualism contradicts the salience that this value is generally assigned in the American creed (Kluegel and Smith 1986; McCloskey and Zaller 1984). Similarly, the clear dominance of economic security belies the post-material nature of American society articulated by Inglehart (1997). On the other hand, the results presented here do align nicely with the recent work which demonstrates that Americans really are more sensitive to economic concerns and material well-being than was previously believed to be the case (Gilens 2012; McCall 2013). And, the wide variability around the "average" value hierarchy is certainly consistent with the view that American culture is composed of disparate and often-conflicting elements (Smith 1993; Wildavsky 1987).

\section{RELIGIOUS AND POLITICAL DIFFERENCES IN VALUE CHOICES}

But, do these obvious differences in value choices provide evidence of conflict in fundamental value orientations? In other words, is this evidence of a culture war in American society? If so, then the value rankings should vary along systematic and identifiable lines. Some likely axes of conflict include religion (both denomination and degree of commitment) and political orientations (party identification and ideology).

In order to investigate these possibilities, we can examine the mean vectors of subgroups defined by the preceding variables. And we can also exploit the properties of directional data to generate criteria for evaluating the statistical significance of the subgroup differences. The angular variation in a set of vectors can be divided into additive within-group and between-group components; these components can be used to perform an "analysis of angular variation" or ANAVA that is directly analogous to a typical analysis of variance or ANOVA (Schiffman, Reynolds, and Young 1981).

The results for these subgroup comparisons are shown in Figures 3 and 4. Each panel of the respective figures shows the mean vectors for a particular set of subgroups. Operational definitions for the variables used to create the subgroups are provided in the Appendix. Just as with the vectors for individuals, the differences of the mean value preferences across the groups are summarized in the angle between the respective groups' vectors; correlations in the mean rankings are still shown as the cosines of the angles between the mean vectors. And, the mean resultant length of each subgroup vector is inversely related to the heterogeneity of the value choices within the subgroups. Note that each of the figures shows exactly the same geometric space. But, the arrowheads of the group vectors and the terminal points of the individual vectors are omitted, and the value points are made smaller in order to emphasize the positions of the subgroup vectors in each panel.
Figure 3 illustrates how religion affects value choices. The first panel shows denominational differences in the mean vector orientations. Here, self-identified Protestants and Christians rank social order, economic security, and morality at the high end. In contrast, the mean vector for people with no religious affiliation shows greater emphasis on equality and freedom, along with economic security. Catholics, Jews, and people who placed themselves in the "Other" category fall in between these patterns, with the former two denominations more like Protestants and other Christians, and the latter more like the nonaffiliated. The differences are statistically significant, with an observed probability value from the ANAVA that is effectively zero. But, even though the value rankings of the denominations differ, it is not entirely accurate to say that they conflict.

The logic behind the previous statement is as follows: Differences in value rankings exist anytime the correlation between two rank-orders is less than 1.0. But, positive correlations indicate that the two value orderings are relatively similar to each other. That is, values that fall at high positions in one ranking also tend to fall at high positions in the other ranking, and vice versa. The values just do not all fall at exactly the same position in both rank-orders. Geometrically, positively correlated rank-orders imply that the angle between the two vectors is greater than zero but less than 90 degrees. On the other hand, conflict in value rankings occurs when the rank-orders are negatively correlated with each other, indicating that values falling at high ranks in one ordering tend to fall at low ranks in the other ordering (and vice versa). The latter would be represented in the geometric model as vectors separated by angles larger than 90 degrees.

Returning to the first panel of Figure 3, the angles between the mean vectors for all denominational groups are less than 90 degrees. This shows that each religion's average value choices are different from, but not opposed to, those from other religious groups. In fact, the smallest correlation in average value rankings is still a fairly robust 0.290 for Protestants and those with no affiliation. Thus, even the biggest differences in value orientations across religions are just not that pronounced.

The differences show up more starkly when we turn to religious commitment in the second panel of Figure 3. This variable measures the salience of religion in the respondents' lives, and for purposes of the figure, it has been collapsed to four categories. The resultant mean vectors show clearly that value orientations change systematically across different levels of religious commitment. People who report little involvement with religion place equality, economic security, and freedom at the top of their importance hierarchies, with individualism, patriotism, and morality near the bottom. In contrast, heavily committed individuals tend to rank morality and social order highest (by a substantial margin) with freedom and especially individualism at the lowest levels importance, also widely separated from the other values. The differences across the groups are definitely significant (ANAVA observed probability value of 0.000$)$. But, the most contrasting 
FIGURE 3. Geometric Model of Value Preferences, Showing Mean Vectors for Religious Affiliations and Levels of Religious Commitment

A. Mean vectors for subgroups defined by religious affiliation

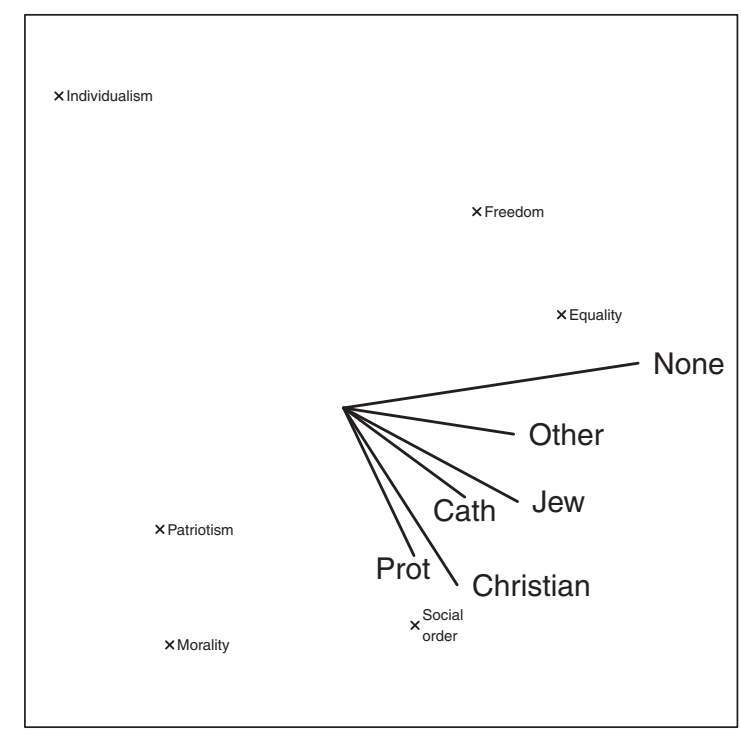

B. Mean vectors for subgroups defined by levels of religious commitment

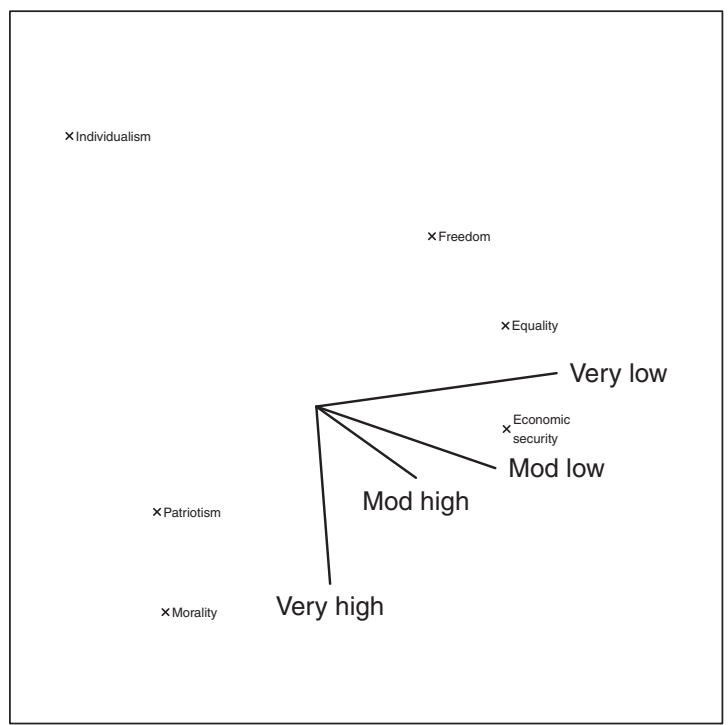

average value hierarchies are more accurately characterized as unrelated, rather than actively opposed: the correlation between the mean vectors for people with the lowest and highest levels of religious commitment is -0.061 .

The results in Figure 3 are particularly interesting, because religious orientations are frequently identified as the basic foundation of the culture war in modern America. Based upon this evidence, such an interpretation seems to be overstated. It is certainly the case that people with different religious backgrounds value different things. But, it would be an exaggeration to say that their values are fundamentally opposed to each other.

Figure 4 breaks down the individual value hierarchies according to symbolic political orientations. This is where clear evidence of opposing value hierarchies comes to the forefront. In both cases, the differences are statistically significant (the observed probability values for the ANAVA F statistics are effectively zero). The mean vectors for the opposing political groups are separated by angles that are substantially greater than 


\section{FIGURE 4. Geometric Model of Value Preferences, Showing Mean Vectors for Party Identification and Ideology}

A. Mean vectors for subgroups defined by party identification

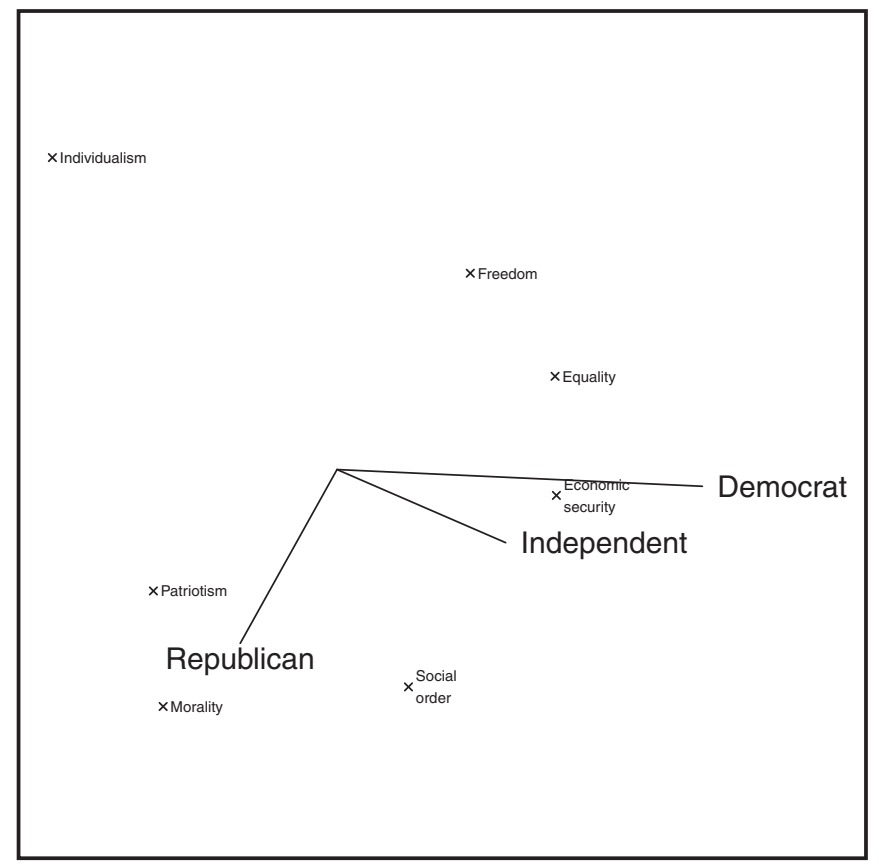

B. Mean vectors for subgroups defined by ideology

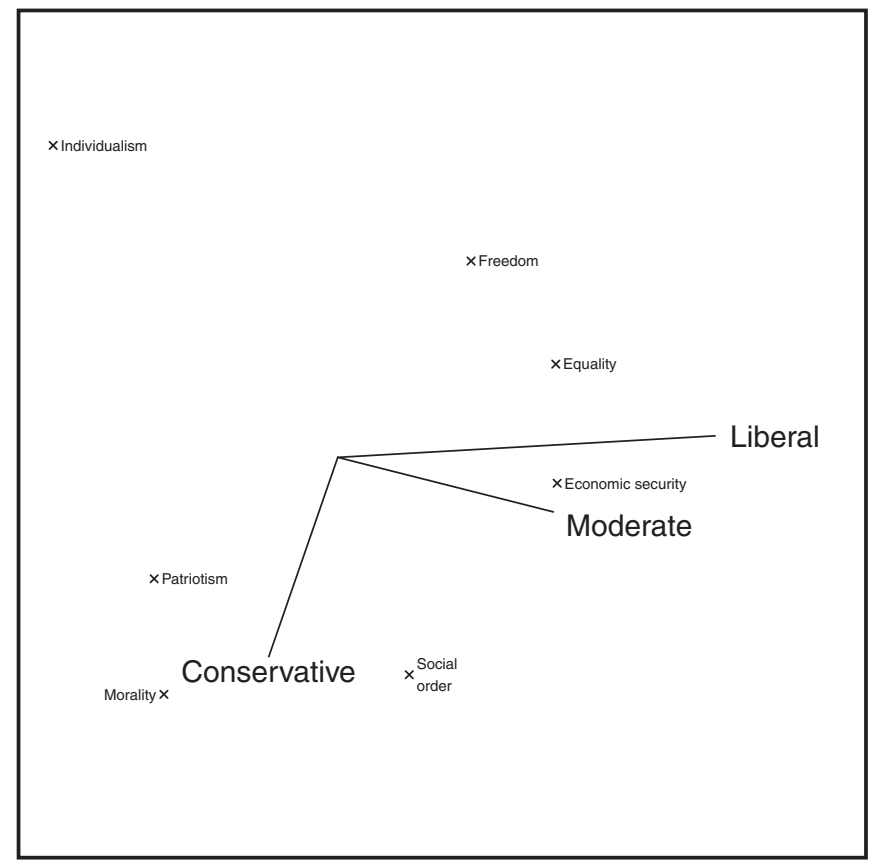

90 degrees, showing that their average value rankings are negatively correlated with each other. Specifically, the correlation between the mean value hierarchies for Republicans and Democrats is -0.446 , while that for liberals and conservatives is -0.380 . Notice, too, that independents and moderates fall in between the re- spective opposing groups. But, independents are much more like Democrats than Republicans, and moderates are more like liberals than conservatives.

So, it seems that the clearest evidence for value conflict is associated with differences in political loyalties and orientations. Republicans and conservatives are 
particularly distinctive from the rest of society in the importance they assign to morality, patriotism, and social order. Democrats and liberals, along with partisan and ideological centrists, place greater emphasis on economic security, equality, and to a somewhat lesser extent, freedom.

Another interesting feature of the two graphs in Figure 4 is the fact that the vectors for Democrats and liberals are both longer than those for Republicans and conservatives, respectively, showing that the former groups are more unified in their value choices than are the latter. At first, this may seem surprising since the Democratic party is often characterized as a coalition of diverse interests, in contrast to a unified Republican party. Nevertheless, the heterogeneity revealed by the relatively short vector for Republicans in Figure $4 \mathrm{~A}$ could perhaps be a precursor to the extended competition between the conservative and moderate wings of the Republican party during the 2012 presidential primary campaign (Skocpol and Williamson 2012). Similarly, the conventional understanding holds that liberals are much more likely to experience value conflict than conservatives (Feldman and Zaller 1992). But, Ellis and Stimson (2012) show that "symbolic" conservatives are actually very heterogeneous in their "operational ideologies," with many expressing preferences for liberal policy stands on specific issues. The value heterogeneity among conservatives shown in Figure 4B may, in fact, provide a foundation for the varied issue attitudes of self-styled conservatives.

\section{THE SOURCES AND MAGNITUDE OF VALUE CONFLICT}

The subgroup comparisons presented so far provide some interesting initial evidence about the ways that religious and political characteristics are related to value orientations. But, they are not sufficient in themselves because they represent bivariate relationships. Furthermore, the subgroups used to break down value choices in Figures 3 and 4 are correlated. Therefore, it is important to examine the simultaneous effects of these and other variables in order to determine whether some combination of them operates jointly to differentiate individual value structures.

In order to evaluate this possibility, I will employ a regression model which explicitly takes into account the fact that the important information about the dependent variable is the angular separation of the respective vectors around the unit circle. This approach, called "circular regression," was developed by Fisher and Lee (1992) and it is presented in a political science context by Gill and Hangartner (2010). ${ }^{7}$

\footnotetext{
${ }^{7}$ Circular regression uses a generalized linear model in which the model specification is as follows:

$$
\mu_{i}=\mu+g^{-1}\left(\mathbf{x}_{i} \beta\right),
$$

where $\mu_{i}$ is the position of the $i$ th observation's vector around the unit circle (in radians, moving counterclockwise from the 3:00 position), $\mu$ is an intercept, $\mathbf{x}_{i}$ is the set of independent variable values for
}

\begin{tabular}{|c|c|c|c|}
\hline & $\begin{array}{c}\text { MLE } \\
\text { Coefficient }\end{array}$ & $\begin{array}{l}\text { Standard } \\
\text { Error }\end{array}$ & $\begin{array}{l}\text { Observed } \\
\text { Probability }\end{array}$ \\
\hline $\begin{array}{l}\text { Respondent's } \\
\text { Age }\end{array}$ & -0.008 & 0.002 & 0.000 \\
\hline $\begin{array}{l}\text { Some } \\
\text { College }\end{array}$ & 0.148 & 0.051 & 0.002 \\
\hline $\begin{array}{l}\text { College } \\
\text { Graduate }\end{array}$ & 0.429 & 0.065 & 0.000 \\
\hline $\begin{array}{l}\text { Religious } \\
\text { Commitment }\end{array}$ & -0.020 & 0.006 & 0.000 \\
\hline $\begin{array}{l}\text { Party } \\
\text { Identification }\end{array}$ & -0.109 & 0.016 & 0.000 \\
\hline $\begin{array}{l}\text { Lib-Con } \\
\text { Ideology }\end{array}$ & -0.140 & 0.026 & 0.000 \\
\hline Intercept $(\mu)$ & -0.951 & 0.044 & 0.000 \\
\hline
\end{tabular}

Note: Cell entries are maximum likelihood coefficient estimates, standard errors, and probability values for one-sided test of $H_{0}: \beta_{j}=0$, obtained from circular regression procedure developed by Fisher and Lee (1992) and presented by Gill and Hangartner (2010).

Table 3 contains the maximum likelihood estimates for the circular regression model predicting the orientation of the individual vectors as a function of a set of explanatory variables (definitions for all of the independent variables are provided in the Appendix). Initially, the model also included regressors for gender, race, family income, religious denomination, and region. But, preliminary estimates showed that none of these additional variables have any effect once those in Table 3 are taken into account. Therefore, they are omitted from the reported model.

The coefficient estimates are treated in a manner similar to any other regression model. $\mu$ is the intercept, so it shows the mean vector orientation (in radians, measured from the 3:00 position) when all of the independent variables equal zero. Given the coding of the variables, this would be a nonleaning independent with moderate ideology, of average age, with no college, and the lowest level of religious commitment. Because circular regression is a generalized linear model, the exact values of the other coefficients are not immediately interpretable. But, positive values indicate movement in a counterclockwise direction from $\mu$ around the unit circle, while negative values indicate that the variable moves the dependent variable vector around in a clockwise direction.

The empirical results from the circular regression make a great deal of sense in substantive terms. The

observation $i, \beta$ is a set of coefficients, and $g^{-1}$ is a link function mapping from the values of the linear predictor $\left(\mathbf{x}_{i} \beta\right)$ into the interval from zero to $2 \pi$. The parameters of the circular regression model are estimated by maximizing a likelihood function based upon the Von Mises distribution. 
baseline, $\mu$, is -0.95 . This corresponds to a vector pointing toward the lower right, close to the 5:00 position. Turning to the regression coefficients (all of which are statistically different from zero at the 0.01 level in a directional test), those for the two education variables both have positive values. This shows that any education beyond high school corresponds to counterclockwise movement in the mean vector, or higher importance rankings for economic security, equality, and freedom relative to social order, morality, and patriotism. The remaining four coefficients are all negative, meaning clockwise movement in the mean vectors. Based upon the coding of the variables, this means that older people, those with greater religious commitment, stronger Republican (or weaker Democratic) identifications, and more extreme conservative (or less liberal) self-placements all tend to place greater importance on social order, morality, and patriotism rather than any of the other values.

The independent variables are measured in different units, and education consists of two dummy variables. Therefore, it is tricky to measure the sizes of the respective variables' effects on value rankings. The easiest way is to simply take the coefficient value times the range for each variable as an estimate of the maximum possible difference in vector orientations due to that variable. Using that strategy, the effect sizes are -0.53 for age, 0.43 for education (i.e., the coefficient for college graduates, which represents the maximum difference from the omitted reference category of high school graduates or less education), -0.24 for religious commitment, -0.65 for party identification, and -0.84 for ideology. Notice that the variable associated with religion-often identified as the main source of the culture war in America-actually has the weakest net relationship to individual value choices. In contrast, the explicitly political variables, party identification and ideology, have the largest effects, followed by age and education.

While the preceding variables contribute to heterogeneity in feelings about values, are the differences really large enough to justify the claim of a culture war in American society? It is difficult to answer such a question using only the information in Table 3 , since the coefficients are not directly interpretable. Instead, we can look at the predicted mean vectors for hypothetical individuals defined by interesting combinations of the independent variables. Specifically, we will begin with the vectors for the two most extreme cases. On one side, there is the youngest strong Democrat, extremely liberal, college graduate with the lowest level of religious commitment; such an individual should produce the largest value for the predicted vector orientation. On the other side, there is the oldest strong Republican, extremely conservative, with a high school education (or less), who is maximally committed to his/her religion; this person would produce the smallest predicted value. After finding these two most extreme vectors, we can take the bisector between them. Then we can take the mean direction of the actual vectors that fall on either side of this bisector. This procedure gives an easy and reasonable way to summarize the extent to which social and political characteristics result in differing value choices.

Figure 5 shows the configuration of value points with the two most extreme vectors and their bisector shown in gray and the mean vectors on each side of the bisector shown as heavy black line segments. Obviously, the two mean vectors point in very different directions; the angle between them is very large, at 130.28 degrees. The projections from the value points onto the two vectors can be interpreted as each value's average importance for the respective subsets of people. On the right side of the bisector, the mean vector lies approximately in the "2:30" direction; equality projects first on this vector, followed closely by economic security and freedom. Social order falls at an intermediate position, while the projections from individualism, patriotism, and morality all intersect at much lower positions. On the left side of the bisector, the mean vector points in approximately the "7:00" position. Here, morality, patriotism, and social order come first, with the remaining four values projecting at much lower positions. The correlation between the two sets of projections is -0.646 . It is not an exaggeration to say that the most important values for one of these subgroups tend to be the least important for the other subgroup.

Note also that the subgroup mean vectors are both quite long: The vector to the right of the bisector has length 0.735 and the one to the left of the bisector has length 0.682 . Recall that the overall mean vector was quite short, with $\bar{R}=0.321$. This is important because mean resultant length is inversely related to the angular separation among the vectors used to calculate the mean. So, these results show that the two subgroups exhibit far less variability in their value importance rankings than does the public as a whole. American public opinion contains two fairly unified sides characterized by value orientations that average out to be near mirror images of each other. This comprises strong empirical support for the culture war hypothesis.

\section{CONCLUSIONS}

In this article, I have developed a geometric model to represent the structure of Americans' choices among a set of core values. The empirical results create a picture of extreme heterogeneity that contradicts any notion of widespread agreement on a set of fundamental principles. The situation does not merely represent differences of degree; instead, the variability in the value rankings is great enough to represent differences in kind. There are widely distributed, almost diametrically opposing views about which values are important and which are not. It seems reasonable to characterize such sharp differences in feelings about fundamental values as the existence of a culture war.

From a theoretical perspective, the results obtained here contradict views of American culture that are based upon widespread consensus regarding a set of core principles (e.g., Devine 1972; Hartz 1955). And, they cast serious doubt on arguments that political conflict in America takes place within relatively narrow 


\section{FIGURE 5. Geometric Model of Value Preferences, Showing Mean Vectors on Either Side of the Bisector Between the Two Most Extreme Predicted Vectors from the Circular Regression of Vector Positions on Social and Political Characteristics}

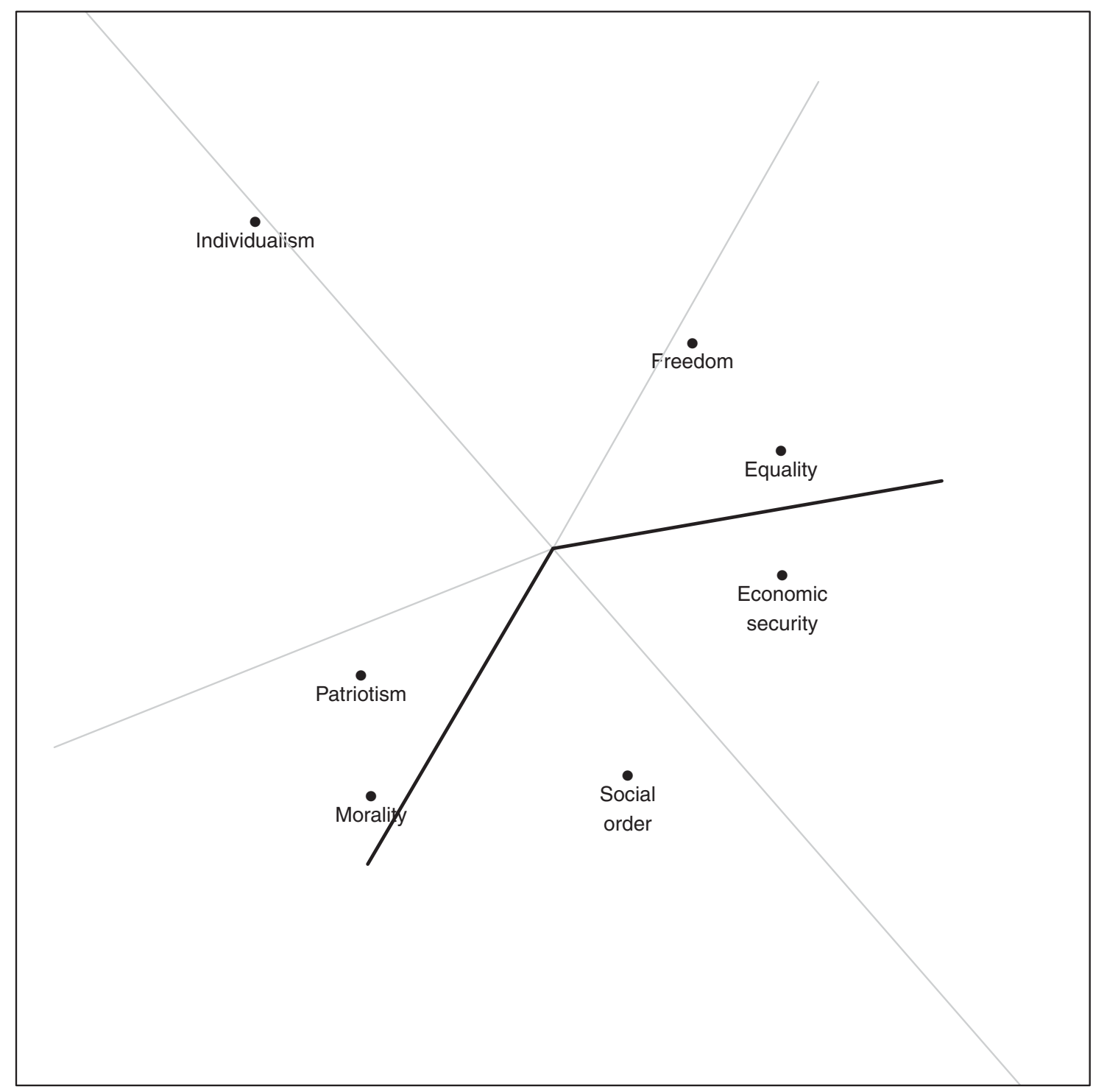

Note: In this figure, the two most extreme vectors and the bisector between them are shown in gray. The two vectors shown in black are the mean vectors of all individual vectors positioned on either side of the bisector.

boundaries of acceptable discourse (e.g., McClosky and Zaller 1984, 4). The high average importance rankings for economic security and social order also suggest that the United States has not yet completed the transition to post-materialism (Inglehart 1997).

On the other hand, the current findings share common ground with theories of culture that posit the existence of mutually conflicting worldviews within society (Douglas and Wildavsky 1982; Wildavsky 1987). This is, in turn, consistent with both pluralistic interpretations of American democracy (Dahl 1989) and the "multiple traditions" perspective on American liberalism (Smith 1993). If, as the latter views suggest, widely disparate value preferences have always existed within American society, then why is it appropriate to characterize the situation in the first decade of the twenty-first century as a distinctive "culture war"? I contend that the answer lies in the clarity with which differences in value choices are connected to sociopolitical characteristics of the American mass public.

When subjected to multivariate analysis, several elements of the "conventional wisdom" about an American culture war do not stand up to scrutiny. For one thing, value orientations are not tightly connected to religious affiliations. And, they are only weakly related to the fervor with which individuals commit themselves to religion. So, the empirical evidence just does not signal the presence of a culture war that emanates from a 
religious divide between fundamentalists and the rest of the American population (e.g., Hunter 1991). At the same time, race-the focus of enormous attention in the political world for many years-does not lead to clear divisions in value choices. This is surprising precisely because there definitely are broad racial differences in opinions on political issues and public policy (e.g., Kinder and Winter 2001). Nevertheless, basic ideas about the relative importance of core values do not seem to be at the heart of these racial differences.

Several other characteristics that are often believed to correspond to political divisions also show little or no connection to values. For example, there are no systematic differences in the value orientations of males and females, despite ongoing evidence of a gender gap in various elements of American electoral politics (e.g., Kaufmann 2006). And, any differences corresponding to income levels or geographic regions disappear once controls are introduced for other factors (McCarty, Poole, and Rosenthal 2006). These findings offer a strong counterpoint to recent work that suggests the existence of class warfare (Murray 2012) or profound differences due to regional political cultures (Chinni and Gimpel 2010).

In contrast, the analysis shows several ways that values do respond to socialization. There are fairly pronounced differences in value choices across age and education levels. While it is only possible to speculate about the exact causes of these effects, it does seem reasonable to suggest that the time period during which a person "comes of age" has an impact on what he or she believes to be the most important ideas to pursue in life (Jennings 2002). The significant effects of the variables gauging schooling beyond high school indicate that higher education does more than merely provide substantive information and knowledge; apparently, it also instills distinctive ideas about the relative importance of different values (Nie, Junn, and Stehlik-Barry 1996).

Perhaps the most striking findings involve the strong effects of party identification and ideology. This confirms that personal value hierarchies can serve as structuring principles to organize political ideas. In the past, values were regarded as an alternative to ideology, providing organizational parsimony for political attitudes among people who did not conceptualize the world in abstract terms (Feldman 1988). To the contrary, the present findings suggest that value orientations actually reinforce ideological distinctions. They provide a substantive foundation for what Ellis and Stimson (2012) call "symbolic" ideology. In other words, the consistency between feelings about value importance and liberal-conservative self-placements shows that the latter are not mere labels, unconnected with other orientations.

The results obtained here also reiterate the explicitly partisan nature of political differences in American society; it appears that the two major parties truly do serve as the focal points for the polarization that many observers have identified in recent American politics (e.g., Bafumi and Shapiro 2009). In fact, the close as- sociation between individual values and political orientations may help explain why the polarization, itself, is so pronounced. Stated simply, there is a lot at stake if people connect their partisan affiliations and issue preferences to their basic beliefs about what is good and bad in the world.

Finally, it is reasonable to ask why this study produced such strong evidence for the existence of serious value conflict when a number of other analyses have reached the opposite conclusion, that the culture war is a myth, or at least, largely exaggerated. The main reason for this important departure from previous work lies in the measurement of value choices. The individual rank-orders used in this analysis come much closer to the theoretical concept of personal value structures than do the approaches used by most other researchers. And, psychological theories of values have long asserted that it is structured choices among competing values, rather than individual values considered singly, that make the difference for human behavior. The results presented here bear out that theoretical stance very nicely.

In conclusion, the geometric model developed in this article relies upon relatively complete depictions of individual value choices to produce an empirical representation of a central component in American political culture. In the past, researchers were hesitant to examine rank-ordered value choices because of the apparent difficulties involved in analyzing such data. But, the model here shows that individual differences in value structures can be represented in a very parsimonious manner by the varying orientations of the individual vectors in the value space. It is precisely the wide dispersion of the individual vectors that provides forceful empirical evidence for the existence of a culture war in American public opinion.

\section{APPENDIX OPERATIONAL DEFINITIONS FOR INDEPENDENT VARIABLES}

Age: Respondents gave their year of birth; that value was subtracted from 2006 to give the age. For the regression analysis, the age variable was centered by subtracting the mean age from each value.

Education: Respondents placed themselves into six categories for not completing high school, high school graduate, some college, a two-year college degree, a fouryear college degree, and a post-graduate degree.

Religious affiliation: Respondents identified themselves as Protestant, Catholic, Jewish, no religion, other Christian, other, and Muslim. Dummy variables were created for the first five denominations. Since there were only two Muslims in the CCES sample, the last two categories are combined.

Religious commitment: A summary variable is created by fitting a nonparametric IRT model (i.e., a Mokken scale) to five survey items. The first asked, "Is religion an important part of your life or not?", the second asked "How many times per week do you pray?", the third asked "Which of the following statements comes closest to your feelings about the Bible?" (with three possible 
responses, varying between "The Bible is a book written by human beings" and "The Bible is the actual word of God"), the fourth asked "Do you attend religious services beyond weddings, baptisms, and funerals?", and the fifth asked "How frequently do you go to religious services?" The commitment variable takes on integer scores from 0 to 12 , with larger scores indicating stronger commitment. The full version of the variable is used for the circular regression, but it is collapsed into four categories for the bivariate graphical presentation.

Party identification: Branching questions were used to create the standard seven-point party identification variable with successive integers assigned to categories from $-3=$ strong Democrat to $3=$ strong Republican. For the bivariate graphical presentation, the variable is collapsed to three categories, with partisan leaners coded as independents.

Ideology: Respondents located themselves along a 0 to 100 scale (presented as a number line on the computer screen) ranging from 0 for "extremely liberal" to 100 for "extremely conservative. The variable is used in its relatively continuous form for the circular regression (recoded to range from -3 to +3 ), but it is collapsed into three categories for the graphical presentation, with liberals as anyone coded 40 or less, moderates from 41 to 59 , and conservatives from 60 to 100 .

\section{Supplementary Materials}

To view supplementary material for this article, please visit http://dx.doi.org/10.1017/S0003055414000380.

\section{REFERENCES}

Abramowitz, Alan I., and Kyle L. Saunders. 2008. "Is Polarization a Myth?" Journal of Politics 70: 542-55.

Almond, Gabriel A., and Sidney Verba. 1963. The Civic Culture: Political Attitudes and Democracy in Five Nations. Princeton, NJ: Princeton University Press.

Alwin, Duane F., and Jon A. Krosnick. 1985. "The Measurement of Values in Surveys: A Comparison of Ratings and Rankings." Public Opinion Quarterly 49: 535-52.

Bafumi, Joseph, and Robert Y. Shapiro. 2009. "A New Partisan Voter." Journal of Politics 71: 1-24.

Baker, Wayne. 2005. America's Crisis of Values: Reality and Perception. Princeton, NJ: Princeton University Press.

Barker, David C., and Christopher Jan Carman. 2012. Representing Red and Blue: How the Culture Wars Change the Way Citizens Speak and Politicians Listen. Oxford, UK: Oxford University Press.

Barker, David C., Jon Hurwitz, and Traci L. Nelson. 2008. "Of Crusades and Culture Wars: 'Messianic' Militarism and Political Conflict in the United States." Journal of Politics 70: 307-22.

Barker, David C., and James D. Tinnick III. 2006. "Competing Visions of Parental Roles and Ideological Constraint." American Political Science Review 100: 249-64.

Bennett, W. Lance. 1980. Public Opinion in American Politics. New York, NY: Harcourt, Brace, Jovanovich.

Berlin, Isaiah. 1969. Four Essays on Liberty. Oxford, UK: Oxford University Press.

Carroll, J. D. 1972. "Individual Differences in Multidimensional Scaling." In Multidimensional Scaling: Theory and Applications in the Behavioral Sciences, Volume I, eds. R. N. Shepard, A. K. Romney, and J. B. Nerlove. New York, NY: Seminar Press.

Chinni, Dante, and James Gimpel. 2010. Our Patchwork Nation: The Surprising Truth about the "Real" America. New York, NY: Gotham Books.
Chong, Dennis. 2000. Rational Lives: Norms and Values in Politics and Society. Chicago, IL: University of Chicago Press.

Ciuk, David J., and William G. Jacoby. 2014. "Checking for Systematic Value Preferences Using the Method of Triads." Political Psychology. Forthcoming. doi: 10.1111/pops12202.

Critchlow, Donald T. 2011. The Conservative Ascendancy: How the Republican Right Rose to Power in Modern America. Lawrence, KS: University of Kansas Press.

Dahl, Robert A. 1989. Democracy and Its Critics. New Haven, CT: Yale University Press.

Davis, Darren W., and Brian D. Silver. 2004. "Civil Liberties vs. Security: Public Opinion in the Context of the Terrorist Attacks on America." American Journal of Political Science 48: 28 46.

Davis, Nancy J., and Robert V. Robinson. 1996. "Are the Rumors of War Exaggerated?" American Journal of Sociology 102: 756-87.

Devine, Donald J. 1972. The Political Culture of the United States. Boston: Little, Brown.

DiMaggio, Paul, John Evans, and Bethany Bryson. 1996. "Have Americans' Social Attitudes Become More Polarized?" American Journal of Sociology 102: 690-755.

Douglas, Mary, and Aaron B. Wildavsky. 1982. Risk and Culture: An Essay on the Selection of Technical and Environmental Dangers. Berkeley, CA: University of California Press.

Easton, David. 1965. A Systems Analysis of Political Life. New York, NY: Wiley.

Ellis, Christopher, and James A. Stimson. 2012. Ideology in America. Cambridge, UK: Cambridge University Press.

Evans, John H. 1996. “'Culture Wars' or Status Group Ideology as the Basis of US Moral Politics." International Journal of Sociology and Social Policy 16: 15-34.

Feldman, Stanley. 1988. "Structure and Consistency in Public Opinion: The Role of Core Beliefs and Values." American Journal of Political Science 32: 416-40.

Feldman, Stanley, and John Zaller. 1992. "The Political Culture of Ambivalence: Ideological Responses to the Welfare State." American Journal of Political Science 36: 268-307.

Fiorina, Morris P., Samuel J. Abrams, and Jeremy C. Pope. 2006. Culture War? The Myth of a Polarized America (Second Edition). New York, NY: Pearson Longman.

Fisher, N. I. and A. J. Lee. 1992. "Regression Models for an Angular Response." Biometrics 48: 665-77.

Gelman, Andrew. 2008. Red State, Blue State, Rich State, Poor State: Why Americans Vote the Way They Do. Princeton, NJ: Princeton University Press.

Gerson, Michael. 2012. "Obama's Recipe for Endless Culture War." The Washington Post, June 18, 2012. http://www.washingtonpost. com/opinions/michael-gerson-our-endless-culture-war/2012/06/ 18/gJQApMhLmV_story.html.

Gastil, John, Don Braman, Dan Jahan, and Paul Slovic. 2011. "The Cultural Orientation of Mass Political Opinion." PS: Political Science \& Politics 44: 711-4.

Gilens, Martin. 2012. Affluence and Influence: Economic Inequality and Political Power in America. Princeton, NJ: Princeton University Press.

Gill, Jeff, and Dominik Hangartner. 2010. "Circular Data in Political Science and How to Handle It." Political Analysis 18: 31636.

Goren, Paul, Christopher M. Federico, and Miki Caul Kittilson. 2009. "Source Cues, Partisan Identities, and Political Value Expression." American Journal of Political Science 53: 805-20.

Guinness, Os. 1993. The American Hour: A Time of Reckoning and the Once and Future Role of Faith. New York, NY: Free Press.

Hartz, Louis. 1955. The Liberal Tradition in America: An Interpretation of American Political Thought Since the Revolution. New York: Harcourt, Brace, World.

Henderson, Nia-Malika. 2012. "Rick Santorum presses culture war attack." The Washington Post, February 26, 2012. http://www. washingtonpost.com/politics/santorum-presses-culture-warsattack/2012/02/26/gIQAqSkicR_story.html.

Hochschild, Jennifer L. 1995. Facing Up to the American Dream: Race, Class, and the Soul of the Nation. Princeton, NJ: Princeton University Press.

Hunter, James Davison. 1991. Culture Wars: The Struggle to Define America. New York, NY: Basic Books. 
Inglehart, Ronald. 1997. Modernization and Postmodernization: Cultural, Economic, and Political Change in 43 Societies. Princeton, NJ: Princeton University Press.

Jacoby, William G. 2006. "Value Choices in the American Public." American Journal of Political Science 50: 706-23.

Jacoby, William G. 2011. "Measuring Value Choices: Are Rank Orders Valid Indicators?" Paper presented at the 2011 Annual Meetings of the Southern Political Science Association. New Orleans, LA, January 6, 2011.

Jacoby, William G., and David J. Ciuk. 2014. "Individual Value Choices: Orderly Structure Versus Ambivalence and Indifference." Working Paper.

Jacoby, William G., and Paul M. Sniderman. 2006. "The Structure of Value Choices in the American Public." Paper presented at the 2006 Annual Meetings of the Southern Political Science Association.

Janda, Kenneth, Jeffrey M. Berry, and Jerry Goldman. 2002. The Challenge of Democracy (Seventh Edition). Boston, MA: Houghton-Mifflin.

Jennings, M. Kent. 2002. "Generation Units and the Student Protest Movement in the United States: An Intra- and Intergenerational Analysis." Political Psychology 23: 303-24.

Katznelson, Ira. 1996. Liberalism's Crooked Circle: Letters to Adam Michnik. Princeton, NJ: Princeton University Press.

Kaufmann, Karen M. 2006. "The Gender Gap," PS: Political Science and Politics 39: 447-53.

Kinder, Donald R., and Nicholas Winter. 2001. "Exploring the Racial Divide: Blacks, Whites, and Opinion on National Policy." American Journal of Political Science 45: 439-56.

Kluegel, James R., and Eliot R. Smith. 1986. Beliefs About Inequality: Americans' Views of What Is and What Ought to Be. Hawthorne, NY: Aldine de Gruyter.

Lakoff, George. 2002. Moral Politics: How Liberals and Conservatives Think. Chicago, IL: University of Chicago Press.

Layman, Geoffrey C., Thomas M. Carsey, and Juliana Menasce Horowitz. 2006. "Party Polarization in American Politics: Characteristics, Causes, and Consequences." Annual Review of Political Science 9: 83-110.

Levendusky, Matthew. 2009. The Partisan Sort: How Liberals Became Democrats and Conservatives Became Republicans. Chicago, IL: University of Chicago Press.

McCall, Leslie. 2013. The Undeserving Rich: American Beliefs about Inequality, Opportunity, and Redistribution. Cambridge, UK: Cambridge University Press.

McCarty, Nolan, Keith T. Poole, and Howard Rosenthal. 2006. Polarized America: The Dance of Ideology and Unequal Riches. Cambridge, MA: MIT Press.

McClosky, Herbert, and John Zaller. 1984. The American Ethos: Public Attitudes Toward Capitalism and Democracy. Cambridge, MA: Harvard University Press.

Maio, Gregory R., Neal J. Roese, Clive Seligman, and Albert Katz. 1996. "Rankings, Ratings, and the Measurement of Values: Evidence for the Superior Validity of Ratings," Basic and Applied Social Psychology 18: 171-81.

Meckler, Mark, and Jenny Beth Martin. 2012. Tea Party Patriots: The Second American Revolution. New York, NY: Henry Holt.

Murray, Charles. 2012. Coming Apart: The State of White America, 1960-2010. New York, NY: Crown Forum.

Nagourney, Adam. 2012. “'Cultural War' of 1992 Moves In From the Fringe." The New York Times, August 30, 2012. http://www. nytimes.com/2012/08/30/us/politics/from-the-fringe-in-1992patrick-j-buchanans-words-now-seem-mainstream.html.

Nie, Norman H., Jane Junn, and Kenneth Stehlik-Barry. 1996. Education and Democratic Citizenship in America. Chicago, IL: University of Chicago Press.

Peffley, Mark, Pia Knigge, and Jon Hurwitz. 2001. "A Multiple Values Model of Political Tolerance." Political Research Quarterly 54: 379-406.
Ripberger, Joseph T., Hank C. Jenkins-Smith, and Kerry G. Herron. 2011. "How Cultural Orientations Crate Shifting National Security Coalitions on Nuclear Weapons and Terrorist Threats in the American Public." PS: Political Science and Politics 44: $715-19$.

Rokeach, Milton. 1973. The Nature of Human Values. New York, NY: Free Press.

Rossiter, Clinton. 1962. Conservatism in America: The Thankless Persuasion. New York: Vintage Books.

Schiffman, Susan S., M. Lance Reynolds, and Forrest W. Young. 1981. Introduction to Multidimensional Scaling: Theory, Methods, and Applications. New York, NY: Academic Press.

Schlesinger, Robert. 2012. "New Culture War Will Help Rick Santorum, Barack Obama," U. S. News and World Report, February 8, 2012. http://www.usnews.com/opinion/blogs/robertschlesinger/2012/02/08/new-culture-war-will-benefit-ricksantorum-barack-obama,

Schwartz, Shalom H. 1996. "Value Priorities and Behavior: Applying a Theory of Integrated Value Systems." In The Psychology of Values: The Ontario Symposium, Volume 8, eds. Clive Seligman, James M. Olson, and Mark P. Zanna. Mahwah, NJ: Lawrence Erlbaum Associates.

Schwartz, Shalom H., and Wolfgang Bilsky. 1987. "Toward a Universal Psychological Structure of Human Values." Journal of Personality and Social Psychology 53: 550-62.

Searing, Donald D. 1978. "Measuring Politicians' Values: Administration and Assessment of a Ranking Technique in the British House of Commons." American Political Science Review 72: $65-79$.

Sears, David O., Leonie Huddy, and Lynitta Schaffer. 1983. "NES Pilot Study of Values (Revised)." Ann Arbor, MI: National Election Studies Pilot Study Report, Number nes002249.

Skocpol, Theda, and Vanessa Williamson. 2012. The Tea Party and the Remaking of Republican Conservatism. Oxford, UK: Oxford University Press.

Smith, Rogers M. 1993. "Beyond Tocqueville, Myrdal, and Hartz: The Multiple Traditions in America." American Political Science Review 87: 549-66.

Sniderman, Paul M., Joseph F. Fletcher, Peter H. Russell, and Philip E. Tetlock. 1996. The Clash of Rights: Liberty, Equality, and Legitimacy in Pluralist Democracy. New Haven, CT: Yale University Press.

Stein, Sam, and Amanda Terkel. 2012. "Mitt Romney's Culture War Distraction: How a Job-Centric Campaign Got Sidetracked." Posted August 24, 2012. http://www.huffingtonpost.com/2012/08/ 24/mitt-romney-culture-war-_n_1827877.html, accessed August 27, 2012.

Stone, Deborah. 2012. Policy Paradox: The Art of Political DecisionMaking (Third Edition). New York, NY: W. W. Norton.

Swedlow, Brandon, and Mikel L. Wyckoff. 2009. "Value Preferences and Ideological Structuring of Attitudes in American Public Opinion." American Politics Research 37: 1048-87.

Treier, Shawn, and D. Sunshine Hillygus. 2009. "The Nature of Political Ideology in the Contemporary Electorate." Public Opinion Quarterly 73: 679-703.

Vavreck, Lynn, and Douglas Rivers. 2008. "The 2006 Cooperative Congressional Election Study." Journal of Elections, Public Opinion and Parties 18: 355-66.

Verplanken, Bas, and Rob. W. Holland. 2002. "Motivated Decision Making: Effects of Activism and Self-Centrality on Values in Choices and Behaviors." Journal of Personality and Social Psychology 82: 434-47.

Wildavsky, Aaron. 1987. "Choosing Preferences by Constructing Institutions: A Cultural Theory of Preference Formation." American Political Science Review 81: 3-22.

Williams, Rhys H. (eds.) 1997. Cultural Wars in American Politics. New York, NY: Aldine de Gruyter.

Wolfe, Alan. 1998. One Nation, After All. New York, NY: Viking. 